\title{
Reflexões sobre as ações para o tratamento dos riscos ambientais nos assentamentos precários de São Bernardo do Campo, SP 1
}

\section{Reflections on treatment actions of environmental risks in the slums of São Bernardo do Campo, SP}

\author{
Silva, Lucas Rangel Eduardo'; Canil, Kátia²; \\ 1 UFABC, Av. dos Estados, 5001, Santo André, SP, Brasil, \\ lucas.rangel.e.s@gmail.com \\ 2 UFABC, katia.canil@ufabc.edu.br
}

\begin{abstract}
RESUMO
Os assentamentos precários no município de São Bernardo do Campo, SP, decorrentes do déficit habitacional, seguem tendência de crescimento concomitantemente com a "construção dos riscos" posto que a ocupação destes territórios é caracterizada pela espontaneidade e autoconstrução, isto é, sem um planejamento formal do Estado. A gestão municipal (2009-2016) exerceu uma política incisiva no enfrentamento dos riscos associados a deslizamentos e inundações. Assim, este artigo tem como objetivo refletir sobre a abordagem corrente do poder público, subsidiado pelo meio técnico-científico, na gestão dos riscos ambientais no meio urbano, discutindo quais foram os acertos e erros das ações tomadas pelo governo local. A análise, realizada a partir de estudos prévios que compreendiam visitas a campo nos assentamentos precários de Vila São Pedro e Parque São Bernardo, recentemente urbanizados, apontou para a insuficiência das medidas adotadas. As demonstrações de reconstrução do risco observadas passam pelas seguintes questões: i) expertise dos responsáveis pelas intervenções; ii) modelo de gestão das cidades; e iii) divergência entre a população e legislação, podendo ser enfrentadas com i) coprodução do conhecimento; ii) controle social na gestão das cidades; e iii) engajamento à favor de leis legítimas, que compõem a participação social em um sentido amplo.
\end{abstract}

Palavras-chave: gestão de riscos, urbanização de favelas, participação social.

\begin{abstract}
The slums in the municipality of São Bernardo do Campo, SP, as a result of the housing deficit, follow a growth trend concomitantly with the "construction of risks" since these territories occupation is characterized by spontaneity and self-construction, in other words, there is no formal planning of the State. The municipal government (2009-2016) executed an incisive policy facing the risks associated with landslides and floods. Therefore, this paper aims to reflect about the current approach of the public power, founded in technical practices and scientific researches, to environmental risks management in urban areas, and the positive and negative actions taken by the local government. The analysis, based on previous studies that included
\end{abstract}

\footnotetext{
${ }^{1}$ SILVA, Lucas; CANIL, Kátia. Reflexões sobre as ações para o tratamento dos riscos ambientais nos assentamentos precários de São Bernardo do Campo, SP. In: II SIMPÓSIO NACIONAL DE GESTÃO E ENGENHARIA URBANA: SINGEURB, 2019, São Paulo. Anais... Porto Alegre: ANTAC, 2019.
} 
field trips to Vila São Pedro and Parque São Bernardo, recently upgraded, pointed the insufficiency of the resolutions adopted. The risk reconstruction cases are grounded on the following issues: (i) expertise of those responsible for interventions; ii) city management model; and iii) conflict between population and legislation, and could be faced with i) coproduction of knowledge; ii) social control in cities management; and (iii) engagement in favor of fair laws, which means social participation in a broad sense.

Keywords: risk management, slum upgrading, social engagement.

\section{INTRODUÇÃO}

A Universidade Federal do $A B C$, em parceria com o Consórcio Intermunicipal Grande $A B C$, realizou em 2016 um diagnóstico habitacional para região que revelou de maneira científica a real dimensão do problema da habitação com o objetivo de nortear as políticas públicas (UFABC, 2016). Neste documento, dois dados sobre o município de São Bernardo do Campo, SP. são fundamentais: i) o déficit interno aos assentamentos precários é 73.450 domicílios; e ii) o déficit externo aos assentamentos precários é 18.766 domicílios, totalizando 92.216 domicílios, cerca de $35 \%$ do total do município de acordo com o último censo de 2010 (UFABC, 2016; BRASIL, 2010). Portanto, é razoável constatar que os assentamentos precários, os quais têm maior relevância no quadro de déficit habitacional, não seguem uma tendência de encolhimento, pelo contrário, além de uma carência interna existe pressão externa para o crescimento do número de moradias autoconstruídas em locais não apropriados considerando as limitações naturais dos terrenos.

Este panorama habitacional no município de São Bernardo do Campo não é recente e combinado com condições específicas do meio físico, como a predominância de morros com embasamento cristalino de micaxisto formando anfiteatros côncavos, resultaram em desastres com perdas de vidas humanas, com registro de 20 mortes no período de 1996 a 2009 (UFABC, 2015; IPT, 2017). Em janeiro de 2009, a troca de gestão municipal deu início a uma política incisiva no enfrentamento do problema que culminou na elaboração de diversos diagnósticos, planos e projetos, entre eles, o Plano Municipal de Redução de Riscos (PMRR), marco importante da mudança de atuação do poder público local frente à gestão de riscos, e os projetos de urbanização de favelas com investimento federal de aproximadamente 1,3 bilhão de reais na região do grande $A B C$, relativos ao Programa de Aceleração do Crescimento - Urbanização de Assentamentos Precários (DENALDI et al, 2016).

Tratados como prioridade no período entre 2009 e 2016, a gestão de riscos e a política habitacional foram transformaram o município de São Bernardo do Campo. Nesse sentido, é com essa preocupação que este artigo pretende se desenvolver, isto é: refletir sobre a abordagem do poder público, subsidiado pelo meio técnico-científico, no enfrentamento dos riscos ambientais no meio urbano, e discutindo quais foram os acertos e erros das ações tomadas pelo governo municipal.

\section{MATERIAIS E MÉTODOS}

O município de São Bernardo do Campo está localizado à sudeste da Região Metropolitana de São Paulo Paulo (RMSP), com área de $408 \mathrm{~km}^{2}$, sendo $66 \%$ em território de proteção ambiental, principalmente a Área de Proteção e Recuperação aos Mananciais da Billings (APRM - Billings) (SÃO BERNARDO DO CAMPO, 2017), Figura 1. Em 2010, último censo realizado, o município contava com 765.463 habitantes distribuídos desigualmente pelo território em 260.637 domicílios (BRASIL, 2010). 
Figura 1 - Mapa do município de São Bernardo do Campo, SP

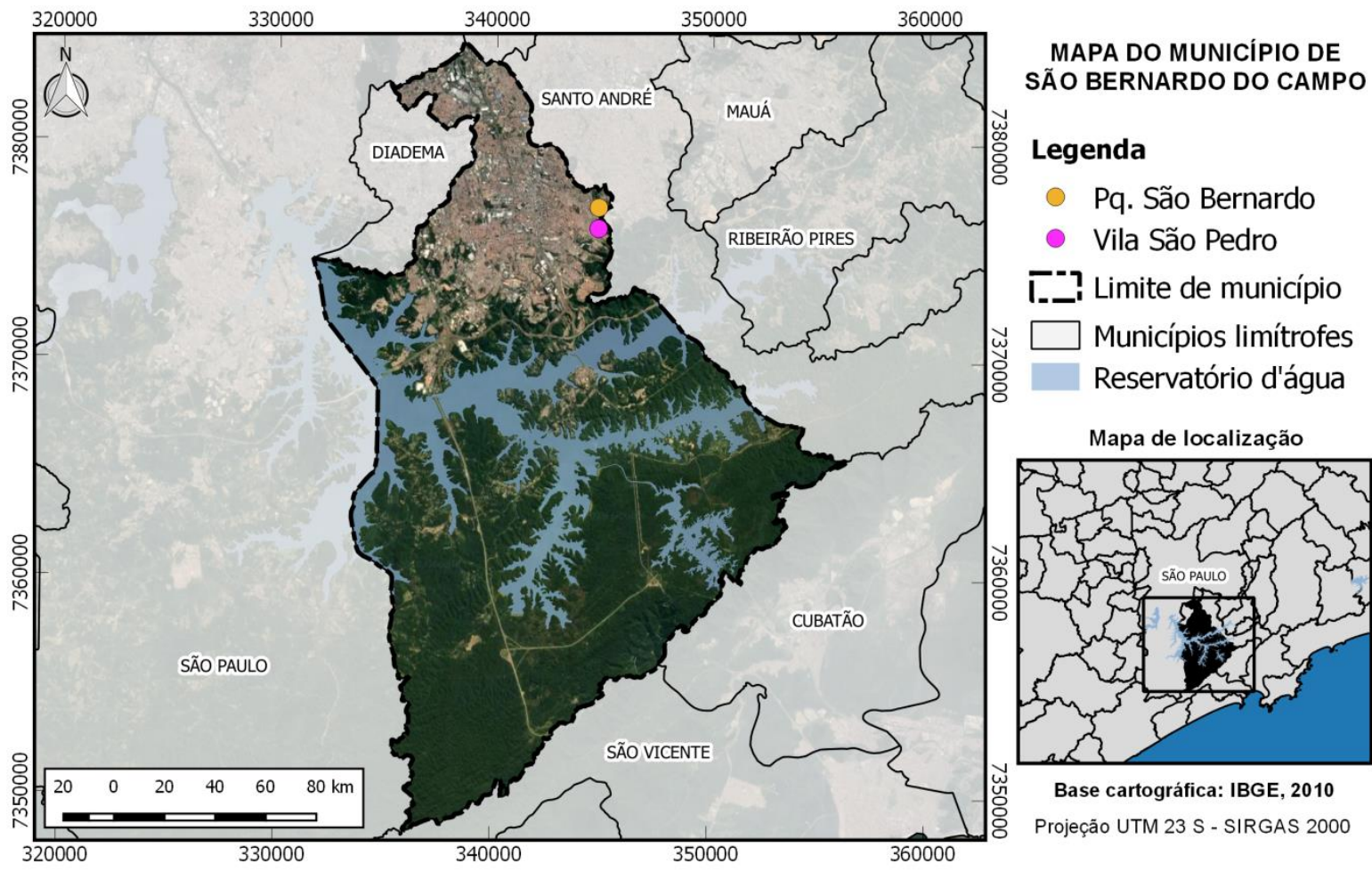

Fonte: Adaptado de Silva \& Canil (2018)

O desenvolvimento desse artigo, fruto da análise dos estudos de Denaldi et al (2016), UFABC (2016) e Silva (2018), considera uma breve descrição da área de estudo e seu contexto frente ao problema habitacional e à situação dos riscos, exemplificando a partir de casos observados no município. Os impactos foram observados e analisados a partir de visitas de campo aos assentamentos Vila São Pedro e Parque São Bernardo, realizadas entre novembro de 2017 e março de 2018. Na ocasião houve o apoio da Defesa Civil municipal na condução do percurso e interlocução com a população local.

\section{O PROBLEMA DA ABORDAGEM NÃO HOLÍSTICA}

No Brasil, as medidas estruturais são consideradas as prioritárias para a gestão pública pois estão ligadas às ações emergenciais, quando o risco está instalado ou o desastre já ocorreu. O entendimento equivocado acerca do assunto por parte dos governantes, importado da ciência moderna, gera um atraso nas tomadas de decisões obrigando estes a preterir as medidas não estruturais, muitas vezes de longo prazo, a obras imediatas. Mesmo o bem intencionado Plano Municipal de Redução de Riscos com seu mapeamento associado, que pode ser considerado uma medida não estrutural, serve, principalmente, como subsídio para as intervenções estruturais na esperança de que estas resolvam o problema, perpetuando a 'cultura do muro de arrimo' (GUSMÃO FILHO, 1995; NOGUEIRA, 2002).

As intervenções realizadas nos assentamentos precários em situação de riscos em São Bernardo do Campo, no âmbito da gestão de riscos e urbanização de favelas, foram de extrema importância para a população e trouxeram melhorias significativas às camadas sociais que conhecem apenas o poder coercitivo do Estado. Entretanto, os problemas encontrados nas áreas de risco persistem mesmo em locais com grande aporte de recursos e apresentam-se comuns a vários municípios.

A Vila São Pedro, o maior assentamento de São Bernardo do Campo, é um caso emblemático no município. O bairro sofreu várias intervenções relacionadas à urbanização e redução do risco, entretanto, o que se observa em visita a campo é a utilização das obras como suporte 
inadequado às novas moradias gerando um cenário de reincidência do risco, este agora atrelado diretamente à medida estrutural e não a falta dela (SILVA, 2018) (Figuras 2a e 2b).

Figura 2a - Cortina atirantada possibilitando a construção de novas moradias no bairro Vila São Pedro / Figura 2b - Escada de acesso às moradias construídas

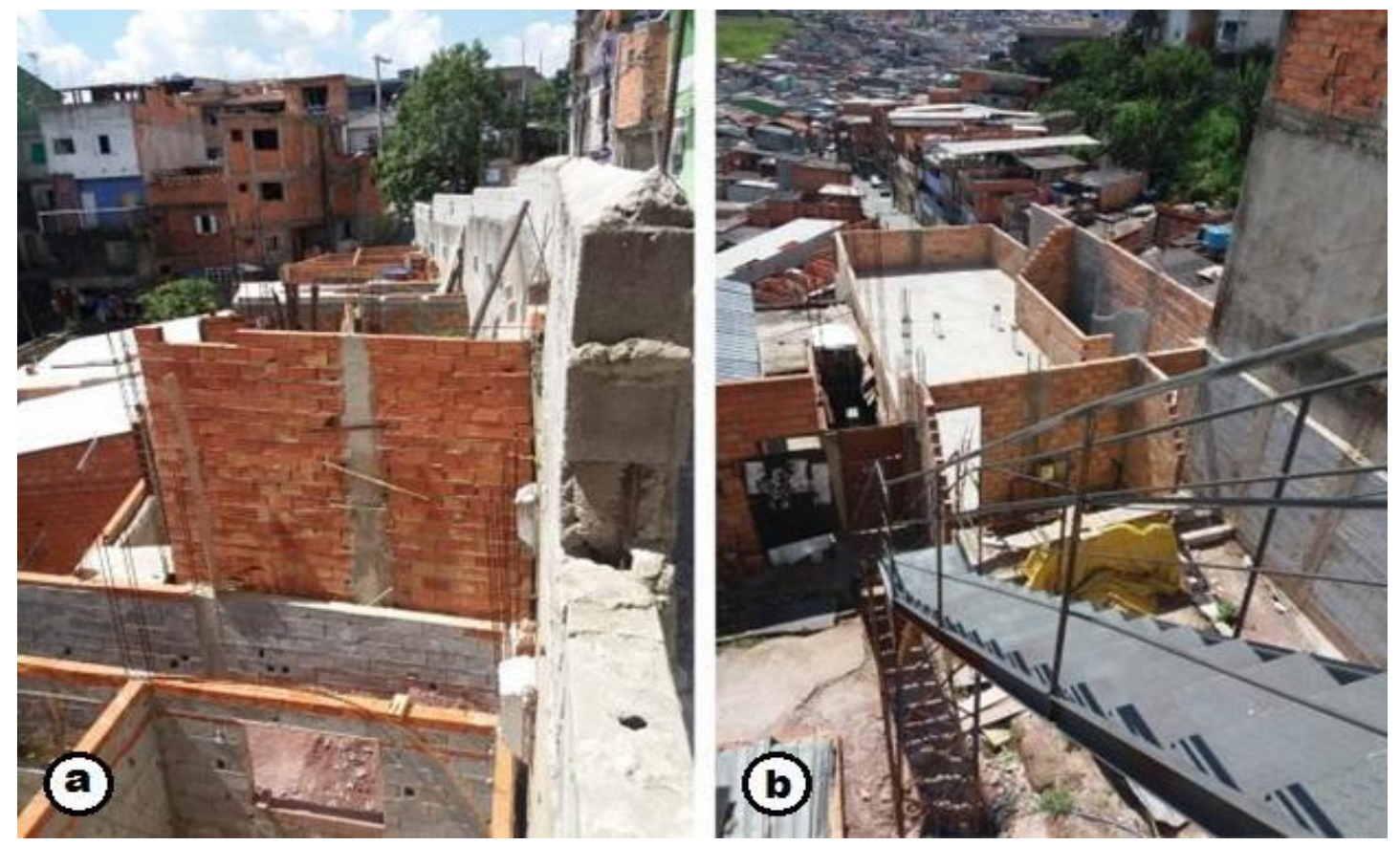

Fonte: DA SILVA, Kattya Roberta Mathias (2017)

O projeto de urbanização no Parque São Bernardo e na Vila São Pedro (DENALDI et al, 2016) não transformou o assentamento precário com as mesmas condições da cidade formal, embora com soluções localizadas, diminuindo o grau de risco, a nova estrutura cria novas formas de precariedade e desigualdade dentro do próprio bairro. Pelas Figuras $3 a$ e $3 b$, fotos do mesmo ponto com perspectivas distintas, é possível observar a discrepância de cada 
realidade presente no assentamento quanto às condições de acessibilidade, segurança, saneamento ambiental e habitação.

Figura 3a - Conjunto habitacional em quadra requalificada com escola pública e comércio local / Figura 3b - Tecido urbano autoconstruído, Pq. São Bernardo
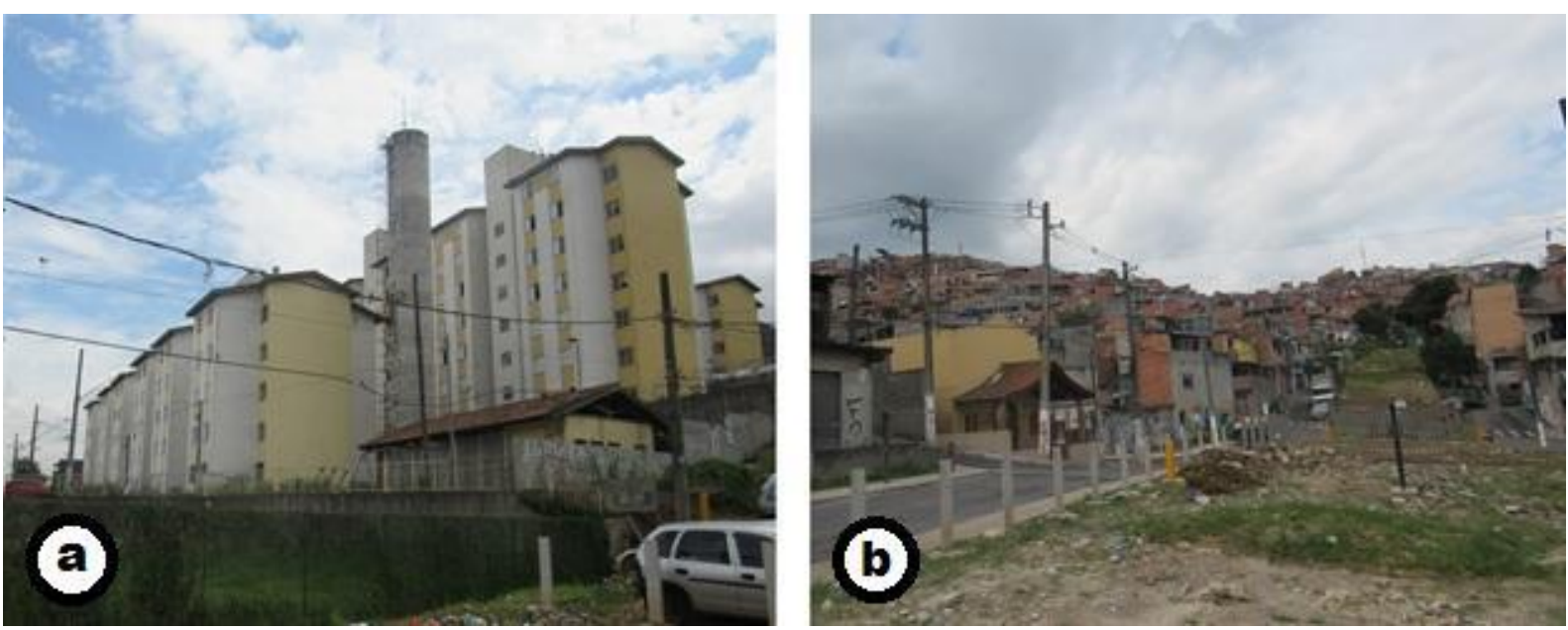

Fonte: SILVA (2018)

\subsection{Participação social: caminho para a evolução na gestão de riscos}

Os riscos ambientais, acentuados pelo déficit habitacional brasileiro, são constantemente reconstruídos pelas transformações do território e aumento da vulnerabilidade das populações. Apesar dos assentamentos precários, como Vila São Pedro e Parque São Bernardo, terem passado pelo processo de urbanização, onde foram realizadas obras de intervenção para estabilidade das condições de riscos, incluindo remoção de moradias e construção de conjuntos habitacionais, não se consideram totalmente integrados ao tecido 
urbano, observando as seguintes questões: i) expertise dos responsáveis pelas intervenções; ii) modelo de gestão das cidades; e iii) divergência entre a população e legislação (Figura 4).

Figura 4 - Fluxograma dos problemas da abordagem na gestão de riscos

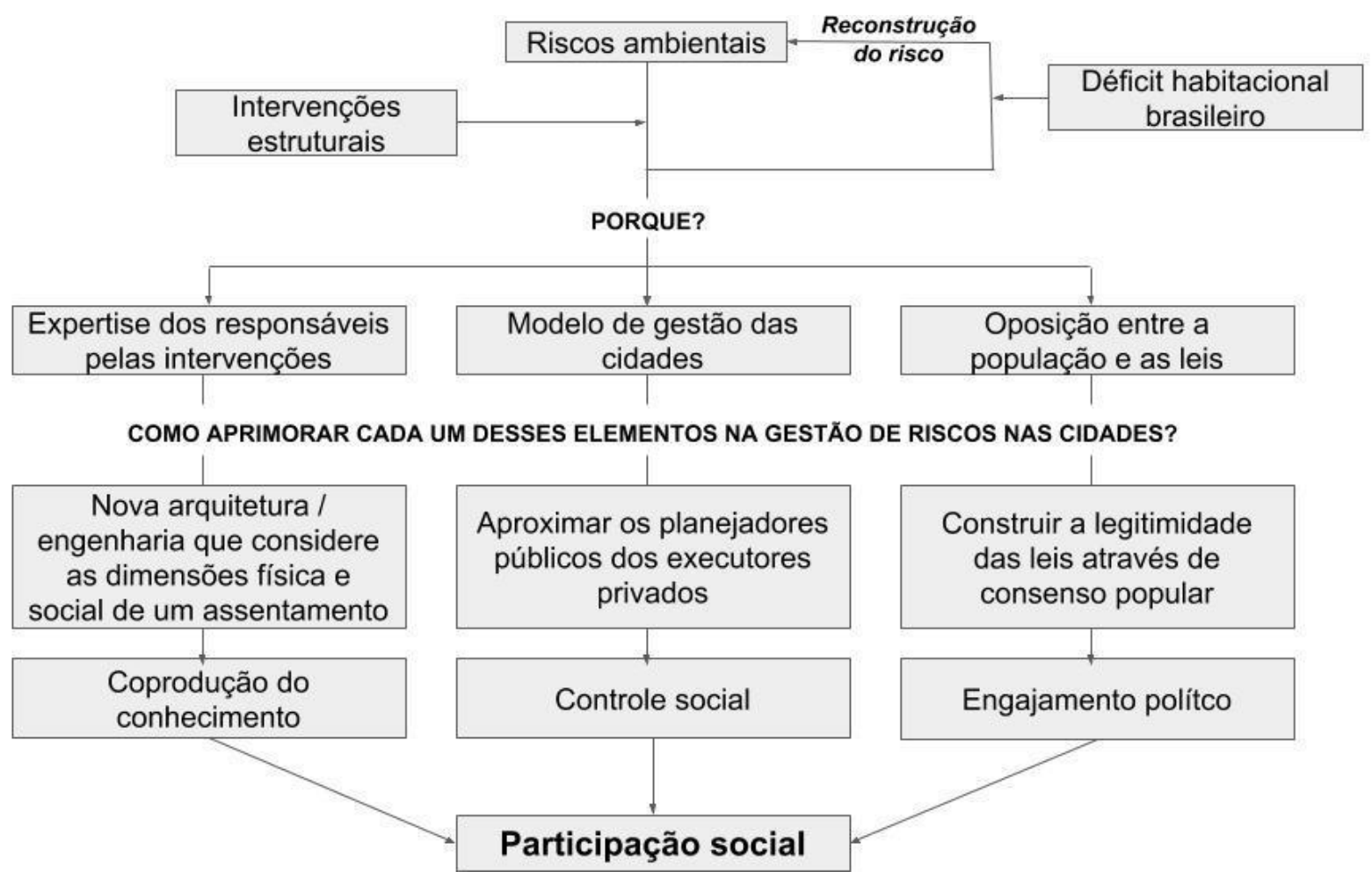

Fonte: Os autores

A especificidade das favelas localizadas em áreas de encostas, ou mesmo margem de córregos, demanda uma nova engenharia e arquitetura que contemplem mais do que a dimensão física por parte dos projetistas. Segundo Zuquim et al. (2016):

\begin{abstract}
"As construtoras detêm o "know-how" para execução de obras viárias, de drenagem e geotécnicas comuns a outras partes da cidade, mas, nos assentamentos precários, estas soluções não são aderentes às características físicas e sociais das favelas: vielas, becos, escadarias e, especialmente, as obras geotécnicas e as áreas livres residuais sem uso." (ZUQUIM et al., 2016, p.7)
\end{abstract}

Medidas desarticuladas que ignorem a vulnerabilidade global destes territórios não passarão de ações mitigadoras, por vezes temporárias. Além de conhecimento técnico estrutural diferenciado para construção segura em áreas com declividade acentuada, ou suscetíveis a inundação, é necessário o entendimento do contexto no qual aquela comunidade está inserida.

O modelo de gestão das cidades brasileiras é caracterizado por uma relação de negócios entre Estado e empresas privadas terceirizadas, respectivamente, cliente e prestadores de serviços (CARVALHO; CORSO-PEREIRA, 2013). Esse padrão é responsável pela contratação de empresas diferentes para ações que deveriam caminhar integradas e acaba por distanciar os gestores públicos da cidade, aqueles cujo dever é garantir as melhores decisões para a população, dos executores das medidas (PULHEZ; FERRARA, 2018). Complementarmente, as ações do poder público estão ligadas a projetos de governos que podem sofrer alternância de comando a cada 4 anos em condições de plena democracia, sob ameaça de paralisação dependendo do resultado das eleições.

No Brasil, as leis são consideradas um ônus aos indivíduos que decidem por respeitá-las. Segundo Coelho (2003), adepto à teoria crítica do direito, fundamentada nas ideias da Escola 
de Frankfurt, o modo de construção do arcabouço legal brasileiro não contempla um envolvimento social e produção da legitimidade das leis, isto é, não há consenso popular sobre a maioria das regras que a legislação institui. Essa reflexão permite entender o porquê as pessoas têm maior apreço por algumas leis do que outras.

Os três aspectos citados anteriormente podem ser aprimorados colocando em prática o princípio da participação social a partir de: i) a coprodução popular de técnicas e conhecimento aplicado à construção em áreas de encosta pode auxiliar na formação de um saber coletivo de uma nova engenharia e arquitetura; ii) o controle social contribui para encurtar as distâncias tanto entre população e empresas terceirizadas quanto entre Estado e empresas. A prática estimula a transparência das atribuições de cada parte no que diz respeito às tarefas, orçamentos e prazos; e iii) o engajamento político da população oferece ferramentas para a defesa de leis baseadas na equidade, em contraponto às leis que perpetuam as desigualdades e consolidam privilégios.

\section{CONSIDERAÇÕES FINAIS}

A gestão de riscos apresenta-se como um tema complexo e interdisciplinar no qual todas suas dimensões devem ser consideradas: ambiental, social, política, econômica, cultural, ecológica e ética. A abordagem atual dos gestores municipais não esgota os problemas das áreas, pois falta uma compreensão holística da temática dos responsáveis pelo o gerenciamento, além de uma governança atuante.

Coprodução do conhecimento, controle social na gestão das cidades e engajamento à favor de leis legítimas compõem a participação social em um sentido amplo, que pode auxiliar na compreensão dos problemas apontados ao longo do artigo. Essas inquietações deram origem ao projeto de extensão Caminhos Participativos para gestão de riscos, que está sendo desenvolvido pela UFABC no ano de 2019 e que deverá trazer novas contribuições para esse debate. As perguntas que deverão orientar os próximos estudos referem-se a práxis, dificuldades e atribuição do poder público em relação à participação social na temática da gestão de riscos.

\section{AGRADECIMENTOS}

Os autores agradecem à Prefeitura de São Bernardo do Campo, pelo apoio da Defesa Civil, sob a coordenação do Geólogo Luiz Antônio Neves Costa, nas visitas a campo realizadas entre novembro de 2017 e março de 2018.

\section{REFERÊNCIAS}

BRASIL. Instituto Brasileiro de Geografia e Estatística (IBGE). Censo Demográfico, 2010. Disponível em: <https://censo2010.ibge.gov.br/>. Acesso em: 17 abr. 2018.

CARVALHO, Inaiá de; CORSO-PEREIRA, Gilberto. A cidade como negócio. Eure, Santiago de Chile, v. 39, n. 118, p.5-26, set. 2013. Quadrimestral. Disponível em:

<https://scielo.conicyt.cl/pdf/eure/v39n118/art01.pdf>. Acesso em: 01 mar. 2019.

COELHO, Luiz Fernando. Teoria crítica do Direito. 3. ed. Belo Horizonte: Delrey, 2003.

DENALDI, Rosana et al. Urbanização de favelas na Região do ABC no âmbito do Programa de Aceleração do Crescimento-Urbanização de Assentamentos Precários. Caderno

Metropolitano, São Paulo, v. 18, n. 35, p.101-118, abr. 2016.

GUSMÃO FILHO, Jaime de Azevedo. A experiência em encostas ocupadas do Recife: integração técnica, institucional e comunitária. Revista do Instituto Geológico, São Paulo, v. , n. 1, p.9-22, 1995. Disponível em: 
<http://www.igeologico.sp.gov.br/downloads/revista_ig/v16nspa02.pdf>. Acesso em: 1 mar. 2019.

IPT - Instituto de Pesquisas Tecnológicas. Vítimas de deslizamentos: Levantamento do IPT de mortes causadas por deslizamentos é tema de reportagem no UOL e Jornal Nacional. 2017. Disponível em: <http://www.ipt.br/noticia/1 190-vitimas_de_deslizamentos.htm>. Acesso em: 25 ago. 2017.

NOGUEIRA, Fernando Rocha. Gerenciamento de riscos ambientais associados a escorregamentos: contribuição às políticas públicas. 2002. 266 f. Tese (Doutorado) - Curso de Geociências e Meio Ambiente, Instituto de Geociências e Ciências Exatas, Universidade Estadual Paulista, Rio Claro, 2002.

PULHEZ, Magaly Marques; FERRARA, Luciana Nicolau. Entre a gestão pública e as empresas privadas: circuitos de conhecimento na urbanização de favelas e nas políticas socioambientais em São Paulo. Pós. Revista do Programa de Pós-graduação em Arquitetura e Urbanismo da Fauusp, São Paulo, v. 25, n. 46, p.56-71, 9 ago. 2018. Disponível em: <https://www.revistas.usp.br/posfau/article/view/140366/146339>. Acesso em: 02 abr. 2019.

SÃO BERNARDO DO CAMPO. PREFEITURA MUNICIPAL DE SÃO BERNARDO DO CAMPO. . Cidade. Disponível em: <http://www.saobernardo.sp.gov.br/web/sbc/cidade>. Acesso em: 22 fev. 2018.

SILVA, Lucas Rangel Eduardo. Análise da evolução temporal dos setores de risco muito alto no município de São Bernardo do Campo, SP. 2018. 76 f. TCC (Graduação) - Curso de Engenharia Ambiental e Urbana, Universidade Federal do Abc, Santo André, 2018.

SILVA, Lucas Rangel Eduardo; CANIL, Kátia. Análise da evolução dos setores de risco muito alto (R4) no município de São Bernardo do Campo, SP. In: $16^{\circ}$ CONGRESSO BRASILEIRO DE GEOLOGIA DE ENGENHARIA E AMBIENTAL - ABGE, 16., 2018, São Paulo. Anais... . São Paulo: Abge, 2018. v. 1, ID 221. Disponível em: <http://www.schenautomacao.com.br/cbge/envio/files/trabalho_221.pdf>. Acesso em: 1 mar. 2019.

UNIVERSIDADE FEDERAL DO ABC. Cartas geotécnicas de aptidão à urbanização dos municípios de São Bernardo do Campo e Rio Grande da Serra - SP. Santo André: Ufabc, 2015.

UNIVERSIDADE FEDERAL DO ABC. Diagnóstico habitacional regional do grande ABC - SP. São Bernardo do Campo: Ufabc, 2016. Disponível em:

<http://consorcioabc.sp.gov.br/imagens/noticia/Diagnostico\%20Habitacional\%20Regional\% 20do\%20Grande\%20ABC_versao\%20final.pdf>. Acesso em: 1 mar. 2019.

ZUQUIM, Maria de Lourdes et al. Remanescência da llegalidade, da Irregularidade, da Precariedade e dos Riscos Pós-urbanização de Favelas. In: SEMINÁRIO NACIONAL SOBRE URBANIZAÇÃO DE FAVELAS, 2., 2016, Rio de Janeiro. Anais... . Rio de Janeiro: Ippur Ufrj, 2016. V. 1, P. $1-14$. 